\title{
DEMENTIA MATTERS: USER-BUILDING INTERACTIONS SHAPING INSTITUTIONAL LIFE IN THE NETHERLANDS
}

\begin{abstract}
Annelieke Driessen
In this article, I examine building-user interactions on three dementia wards in the Netherlands. I coin the concept of "sociomaterial awareness" to articulate a collective situational sensitivity to the ways in which the built environment invites its users (professionals, but also people with dementia themselves) to act in specific ways, as well as to possibilities to adjust (elements of) the building. I argue that along with different enactments of dementia, different positions become available for residents when the built environment is acknowledged as actively shaping care interactions.
\end{abstract}

Keywords: The Netherlands, built environment, care, dementia, institutions, modes of ordering.

Running title: Dementia matters

Media teaser: In describing and theorizing how building-user interactions shape lives on the dementia ward, I develop the notion of "sociomaterial awareness." 
ANNELIEKE DRIESSEN is a medical anthropologist. She conducted her $\mathrm{PhD}$ research at the University of Amsterdam on everyday life and care practices that enact good subject positions for people with dementia. She is currently a Research Fellow at the London School of Hygiene \& Tropical Medicine in the Forms of Care project, where she is conducting ethnographic research on "active non-interventions" in palliative care settings in the UK. Address correspondence to her at: Department of Health Services Research and Policy, Faculty of Public Health and Policy, London School of Hygiene \& Tropical Medicine, 15-17 Tavistock Place, WC1H 9SH, London, UK. E-mail: annelieke.driessen@1shtm.ac.uk 
During my fieldwork in nursing homes for people with dementia in the Netherlands, a recurring theme in conversations among care professionals, and between them and me, was how to deal with what staff considered to be problematic situations. These situations most often involved residents who acted in an agitated or aggressive way, who were restless during the day, or sleepless at night. Sometimes, actions and states were ascribed to dementia, implying that they had to be accepted. Sometimes, care workers tried to prevent or change these actions or states. In this article, I analyse attempts that pertain to the built environment and its use. I demonstrate that acknowledging building-user interactions as relevant to the ways in which situations on the ward unfold, opens up possibilities to shape better ways of living on the ward.

In recent years, there has been growing research on design features of nursing home buildings that are beneficial for people with dementia. The idea is that design promotes good care and quality of life on the ward. "Good design" is currently stipulated to include, for instance, toilets that are visible from the living room so that they can be easily spotted by residents; windows that do not reach all the way to the floor as they might be mistaken as doors; walking circuits and access to outside space that provide the possibility for and invite physical activity. Equally crucial are interior design features such as corners in which residents who walk can find some rest, railings on walls, evenly coloured floors, active and inactive chairs, and multisensorial environments (Verbraeck and Van der Plaats 2016).

By the same token, the costs of "poor design" are high, and immediate. Environmental psychologist Fiona de Vos (2013:20) has argued that poorly designed care home buildings may exacerbate symptoms associated with dementia. Similarly, Bob Verbraeck, coach in dementia care, and Anneke van der Plaats, nursing home geriatrician, have argued that an unfavorable environment for people with dementia results in more "problem behavior" (2016:36). ${ }^{1}$ Importantly, these studies urge us not to ascribe "problem behavior" to an underlying brain disorder, but to consider the environment in which it unfolds instead. 
A recent sociological study argues that buildings enable or discourage certain practices within their walls; in doing so, they are active in the enactment of certain ideologies, be it of care, health or well-being (Buse et al. 2016:2). Given that the life span of care buildings in the Netherlands is generally at least three or four decades, it thus becomes important to consider what ideologies have been "built into" buildings. Take for instance the buildings that were constructed in the post-Second World War era in the Netherlands. As the government assumed responsibility for providing long-term care in the rapidly expanding welfare state (cf. Van Oorschot 2006), residential care and nursing homes were built in a climate of housing scarcity, lack of funds, and regulations for architects to keep costs to a minimum. In 1963, the government encoded quality standards for nursing homes to prevent inequalities in the services offered and resources used for construction; the law regulated the size of resident rooms, width of hallways, types of ceilings, and even height of toilets, explaining the striking similarity between buildings of that period (Targhi Bakkali 2016). Buildings from the mid-70s onwards were designed within a similar normative framework of cost-efficiency, but are better adapted to specific target groups. Buildings from the 2000s are informed by the desire to accommodate tailored (op maat gesneden), small-scale living arrangements (kleinschalig wonen), care and service provision.

As long as a building is in use, it continues to enact these ideologies. Design makes the social, which is never outside but in the objects, hold (Yaneva 2009). This is a time-specific social, which may or may not correspond with the knowledge and values prioritized for present day dementia care. A design, then, cannot be thought of as "good" in and of itself, for what buildings do (cf. Gieryn 2002) does not take place in isolation. Instead, buildings act in interaction with their users, who are both acted upon by the building and act on the built environment (Brand 1995; Law 1992:381; Martin et al. 2015:1018; Nord 2011a). For instance, it is crucial for the well-being of dementia care home residents that access to private space is 
ensured by carers (e.g. Bland 1999; Barnes 2006; McColgan 2005; Nord 2011a; Twigg 2000). This requires built spaces that residents can access, but also people to accompany them there. Similarly, open-door policies have been proposed to be of prime importance: opening the institution's doors can decrease feelings of anxiety, and, paradoxically, the urge to walk away. But here too, a lot of work is required to make the open door policy possible in practice (Driessen, Van der Klift, and Krause 2017; Wigg 2010). These examples bring into view the ways in which space is used, and adjusted, and by whom - and what differences these interactions make for those who live on the ward.

How user-building interactions matter for residents diagnosed with dementia became most clear to me in a story that physiotherapist André told me. Until just three years prior to the start of my fieldwork in 2014, care workers used to lock the toilet doors of the dementia ward. It was assumed that residents did not need access to the bathrooms because care workers took (and still take) them on "toilet rounds" [toiletrondes] at fixed times during the day. ${ }^{2}$ Outside these timeslots, the bathroom spaces were used to store patient lifts instead, saving space elsewhere and saving staff time to fetch them when they were needed. Locking the toilet doors thus ensured that nobody would trip over them when entering the bathroom during an unattended walk on the ward. However, newly admitted residents were often continent when they came to live in the home: they were able to locate the toilets by themselves when they needed them, or would search and find them. But with the doors locked, they could not access them, and unless they found somebody with keys in time, they could do nothing but soil themselves. Rapidly after their admission, these residents too would then become incontinent, thereby seemingly confirming the assumption that incontinence is an inevitable feature of dementia.

When observations accumulated of this, the manager and the care workers realized that the assumption that people with dementia inevitably become incontinent and the resulting 
practice of locking doors makes bodies incontinent. They decided to leave the toilet doors unlocked from then on, and to store the lifts elsewhere.

The story illustrates how fears about institutional life may materialize not merely through design (location of toilets, presence of doors and locks, signposting), but also through interactions with the building. After all, doors do not lock themselves; they must be locked by those who hold keys. The tendency to understand people with dementia as a homogeneous group, "a batch of similar others," is characteristic of "total institutions" (Goffman 1961: 6), and risks producing precisely the realities that institutions purport to alleviate.

Central to these interactions is an imaginary of dementia as an inaccessible and inevitable process of decline. In the words of Science and Technology scholar Ingunn Moser, who uses the concept "modes of ordering" to bring out the ways in which people with dementia are enacted in different ways, this imaginary orders dementia as an objective reality in individual brains or brain tissues. In doing so, it distributes any possibility to act upon the disease away from those who live with it and those who care for them. Rather than being interested in the form orders take, the term "modes of ordering" (Law 1994; Moser 2005) shifts the focus from "order" as a noun, to "ordering" as a verb (Law 1994:104-10; Mol 2010:262). This theoretical move circumvents a problem which often characterizes poststructuralist thinking, namely that "in principle discourse is a contingent pattern," but that "(i)n practice, it tends to behave like necessity" (Law 1994:107). The analytical focus on "modes of ordering" thus emphasizes that discourses do not order the world in a coherent, singular manner. The term insists on the ongoing work involved in the "practical arranging of people and things" (Vogel 2016:24), staging particular relations which may result in different versions of disease, bodies, and subject positions.

The somaticizing mode of ordering obscures the fact that the course of dementia takes shape within relations (see also Hughes, Louw, and Sabat 2005; Kitwood 1997; Kontos 2004). ${ }^{3}$ 
Relating this to the example above, what is perceived to be a "symptom," part of an unavoidable process of decline, may upon closer inspection be partly produced by the built environment (Devlin and Arneill 2003; Verbraeck and Van der Plaats 2016; De Vos 2013:20) and the way its users dwell in and interact with it. Would these people have become incontinent if the doors had been left unlocked? Possibly. One could even say that this is likely. But to assume that residents - as a collective - are either incontinent or unable to find the toilet by themselves, works as a self-fulfilling prophecy. If this is taken as a legitimization to lock all toilet doors (even if to save space and time), then residents might simply be made incontinent.

In a classic material semiotic argument, Law suggests that buildings tend to hold their shape better than other social arrangements: they are configured in ways that produce their "material durability" (2009:9). At the same time, they are not entirely stable. How buildings may be acted upon becomes imaginable if they are no longer perceived as static entities, but as a network of "architectural elements" (Koolhaas, AMO and Harvard Graduate School of Design 2014). ${ }^{4}$ Some architectural arrangements cannot be changed in daily care practice because they would require large interventions like reconstruction. Yet one can "tinker" (Mol 2008; Mol, Moser, and Pols 2010) with the furniture and objects that can be more directly controlled by care workers and residents in daily care (Nord 2011b:51). These practices may be grouped under the relational mode of ordering, in which "dementia presents itself as a growing mismatch and problem with relations between the patient, the daily environment and fellow beings" (Moser 2011: 714). A re-ordering may be observed in the story of the toilet doors: the unlocking of doors enacts dementia differently, opening up the opportunity to live continent on the ward, even if only for a while longer.

Echoing Moser (2011), then, I contend that dementia can, within limits, be acted upon. Here, I am particularly interested in alternative orderings, which come about by acknowledging the built environment as actively shaping situations on the ward, acting upon the building in an 
attempt to prevent or change these situations. My analysis is guided by the following questions: How does the building become relevant to situations that care professionals regard to be problematic? How do care professionals adjust the building or its use to create other ways of living on the ward? How is dementia reordered in the process?

In what follows, I describe the methods I used in my research on the dementia wards of three nursing homes in the Netherlands. I present and analyse three stories of building-user interactions on the dementia ward. I develop the concept "sociomaterial awareness" to articulate a sensitivity to the ways in which the material environment co-shapes ways of living, and in which the building or its use are consequently adjusted, effecting other care practices, and other lives that were possible but which were not (yet) being realised.

\section{RESEARCHING WAYS OF LIVING ON THE WARD}

While architectural studies are concerned with the design of buildings in themselves, ethnographic observations elucidate "acts" of architectural elements and the buildings' users in building-user interactions. In order to research how the building acts and is acted upon in care practices, I draw on ethnographic fieldwork that I conducted on the dementia wards of three Dutch nursing homes in the Netherlands, one of which, De Parkhoeve, ${ }^{6}$ features in this article.

In my methods and analysis, I take on sensitivities characteristic to material semiotics (Law 2009; Mol, Moser and Pols 2010; Moser 2005, 2008; Moser and Law 1999; Pols 2011; Vogel 2014, 2017). Material semiotics assumes that "nothing has reality or form outside the enactment of ... relations. ... It tells stories about 'how' relations assemble, or don't' (Law 2009:141). In other words, the way in which relations assemble creates realities. Material semiotics seeks to interfere in these relations, by working towards "new intellectual tools, sensibilities, questions, and versions of politics" (Law 2009:150). 
Data were collected over a period of 14 months between April and June 2013, and April 2014 and June 2015. Fieldwork in the first location was a pilot study that comprised ten days of observation on the wards. In the latter two locations, fieldwork consisted of participant observation during visits lasting between two and eight hours, on at least three days a week. I wrote up my notes as soon as possible upon leaving the field. I initially focused on the care interactions during washing, getting dressed and eating, so-called "activities of daily living." To learn how residents spent their days when care workers were not directly attending to them individually, I also spent time with residents outside of their daily care interactions. In these participant observations the building and its routine uses made themselves known in many different ways: walls determined which way we could go; walking circuits with balustrades granted us views over lower floors; locked doors prevented our entry to specific parts of the building. These architectural elements affected them and me, albeit not necessarily in the same way or manner: the view of a dead end to a hallway was frustrating; a closed door was unintelligible to most residents; the view of the ground floor led many residents to ask, "How can I get there?," leaving me at loss for an answer. These encounters with elements of the building led me to pay closer attention to, and make more detailed notes on, how the built environment played a role in inviting certain (inter)actions. ${ }^{7}$ These notes are the basis for the analysis presented here.

Family members of residents were informed of the study through the newsletters of the respective care institutions and could indicate if they wished to opt out. I introduced the study to care workers using information leaflets and through an introduction of the research in a few hand-over meetings in the nursing homes, and whenever a new employee arrived. Care worker participants provided oral consent for this part of the study. All residents who had a dementia diagnosis and were admitted to the care institution because they were deemed to require 24hour care. Rather than regarding consent as something that could be asked for and given once, 
I tried to ensure that at all times resident participants were as aware as possible of the contents of the study and were comfortable with my presence (cf. Dewing 2007). Whenever I felt this was not the case, I stopped observations and note taking.

Below, I first describe the building of De Parkhoeve in which the two dementia floors are located. At the time of research, in 2014 and 2015, the building was about 30 years old. Typical of the care home buildings built in the Netherlands around 1985, the wards are located upstairs, while the offices, practice rooms, the restaurant, and the "psychogeriatric garden" are located downstairs (cf. Targhi Bakkali 2016). Each of the two floors consisted of two wards, that were connected via two "walking circuits": one ran through the wards' living rooms and past the residents' rooms located on the outer walls of the building, and the other ran around the nursing station, the bathrooms and the storage rooms. All wards had a closed-door policy; a code to access the lift was required; and the doors leading to the staircases could only be opened with a key that staff, family members, selected residents, and I as the ethnographer, carried. Only two of the nearly 50 residents who lived on the ward at the time knew the code for the lift, and although residents could see the ground floor from the inner walking circuit, they could not go there unless somebody accompanied them.

\section{MOVING FURNITURE, MAKING INVITATIONS}

On a typical day on the ward, many residents spent most of their time sitting or dozing at the same table. Care professionals sometimes flagged this as problematic. But while sometimes this passivity was described to me as a characteristic of dementia, it was also sometimes described as open to change: with the right kind of invitation, residents could be "enticed" into becoming a bit more active.

Organized activities on the ward, such as the collective reading of the newspaper, singing songs from the old days, or gymnastic class, most clearly extended invitations to 
become active. But invitations were also made outside of these activities. Physiotherapist André pointed out to me how the material environment played a role in making invitations to people on the ward. He took me along to test chairs in order to decide which ones would be used for the living rooms. Sitting on several different chairs while listening to André's articulations of their characteristics, I learned that a slightly tilted back rest invites the sitter to lean back and relax, and that an upright back rest invites the sitter to sit "actively" and, after a while, get up again. This sensitivity to the ways in which the built environment and its uses afford particular actions and not others, I call "sociomaterial awareness." It brings into view possibilities of adjusting elements of built environments as part of everyday care practices in order to enact different ways of living on the ward.

Let me provide another example. Upon concluding that the living room did not currently feel much like a home, because it "hardly allowed a 'normal' way to spend the day," activity attendant Janneke and the team of care workers made handy use of this "activating" feature of furniture. Janneke asked me, "Would you have breakfast at the table, then stay there and have coffee, and then stay there and have dinner?" Answering her own question, she continued: "Of course not! You would also have your coffee in the living room, or in a chair that was more comfortable, while reading something, and have breakfast and dinner at the dinner table." Whereas the tables had formerly been arranged in two large tables of eight residents, and three smaller ones for two to four residents, care staff now positioned them differently as to make tables for a maximum of four people. This allowed for residents to sit closer together, and to provide more opportunities for conversation. When crafting a sense of familiarity in the space, and rearranging the furniture to extend invitations for movement, the team acted on their sociomaterial awareness to enable better ways of living on the ward.

The team also arranged a couch for the newly created "coffee corner" and actively stimulated residents to leave the table after meals and go and sit there. They decided to put no 
television in that corner, to create a contrast with the other living room, and to facilitate interactions between residents, and residents and staff. The material equipment of the room now invited physical movement and enabled coffee drinking in places other than where the three meals of the day were served. The extra 20 meters of movement per day could really make a difference for residents who moved only infrequently. They invited residents to lead more active lives than those otherwise afforded, and otherwise expected of people diagnosed with advanced dementia. ${ }^{8}$

\section{PROVIDING KEYS, PROVIDING ACCESS?}

Increasing access to rooms increases privacy, and privacy makes for better ways of living on the ward (cf. Bland 1999; McColgan 2005; Nord 2011a). Yet, while the toilet doors were unlocked, the doors to the residents' rooms remained locked throughout the fieldwork period. When prompted, most care workers argued that not letting residents into their rooms (where there is no "attendance") prevented residents from "rummaging" (rommelen), a term used as a further specification of "restlessness." If residents were in the shared areas, care workers could oversee all their activities and, thus, they argued, tend to their well-being. Janneke told me that opening the doors to residents' rooms is also difficult because "residents take all kinds of things from rooms that then get lost. Like Mr August, who takes everything: dentures, hearing aids... and then we find them later, in the closet, or in the piano.... Or people lie in another resident's bed, and when the resident [whose bed it is] returns to his or her room, there's a fight."

With the doors locked, some residents spent large amounts of time in front of their doors, or "bothering" care workers for the key to their private rooms. ${ }^{9}$ Locked doors did not just prevent restlessness; they produced it. Ms Maren, for instance, often looks like she is on the verge of despair. I know she may well be: we are walking the halls together looking for her room, and when she finds it, she cannot enter. Her own attempts to resolve this situation reflect 
her restlessness: "Who has a key?" she asks those passers-by she suspects carry keys. She asks everybody she sees, but they do not answer her anymore, or they call out while bustling past us. They are on their way to fill out the form about who drank what today, who defecated how much and in what form, to help the lady who just fell, to try again to convince the resident who did not want to take his pills this morning to do so now. In an attempt to keep her away from her room, but in effect never answering her questions, they call out: "You are welcome in the living room! Nurse Jantien is there; she has coffee." Although I carry a key I am unsure about going against the unwritten rules of care workers that say not to open the doors - they tell me being alone in her room makes Ms Maren restless. I often ask if I can open her door - sometimes they say yes, sometimes they encourage me to simply take Ms Maren along to drink more coffee.

Restlessness and repetition feature prominently in biomedical descriptions of dementia. Here, because of the way the built environment is used, they seem necessary: Ms Maren's problem remains unresolved as long as the door to her room is locked. In finding her door locked, she repeats her concern to everyone: "I cannot access my room; who has a key?." It makes her restless. It makes her repeat her questions. The closed door enacts Ms Maren as a person repeating herself, as resonating with how staff already see her - they tell me she is a whinging old lady, and most likely "she has always been this way." Living her life waiting in front of the door to her room, asking for a key, Ms Maren embodies the public nightmare of what it is like to live in residential dementia care.

Ms Maren's care workers discussed whether she might be exempted from the general rule not to let residents into their rooms. They "tinkered" (Mol, Moser, and Pols 2010) with the situation by attaching a key, which took the shape of a door handle (Figure 1), to her walker in order to prevent it from getting lost. Every time Ms Maren sees it, she sees it for the first time. "What is that?" she asks. "It is a key. I know it looks strange, but you can just click it onto your 
door and open it." Her care workers and I show her every time, to no avail. For Ms Maren, the object is too strange to be memorable, too much unlike a classic key for her to recognize it as one. Here, to affect social relations in the desired way, ${ }^{10}$ the key must be recognisable to the person who is to use it. This way, it elicits only incomprehension, voiced as repetitious questioning: "What is that?"11

The key did not solve the situation, but it did alter it $;^{12}$ by being attached to her walker, at least the permission to enter the room had materialized. Now when Ms Maren asks those who pass by to help her, they can offer their help. The key thus connects Ms Maren, the key and those around her in new ways.

However, Ms Maren still spent her time in front of her

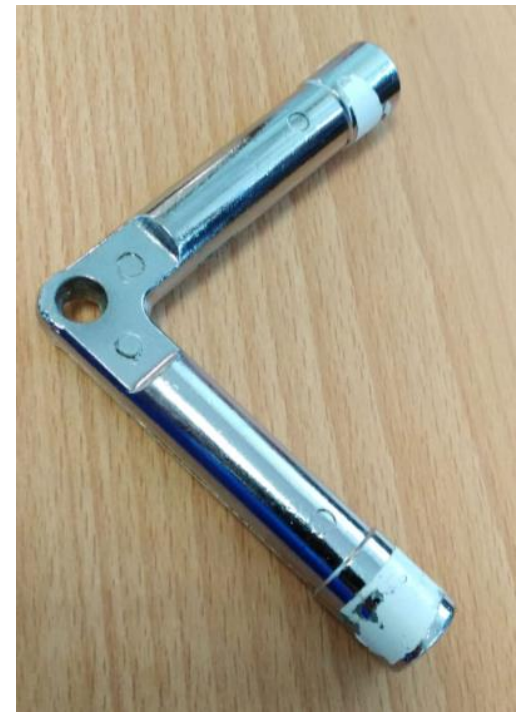
room, waiting. Physiotherapist André asked me if disappearing objects are really such a problem. He proposed an alternative adjustment: "We could have lockers for valuable stuff." Changing the material conditions in all resident rooms by using lockers would be consequential: it would provide all residents access to their rooms, while expensive hearing aids could be stored safely, preventing their loss in closets or in the piano.

Using lockers, of course, does not exclude residents being “checked upon.” Are they restless in their rooms? Would a coffee in the living room help them to feel better? The tinkering continues. If something works, it often does so for a limited time. This procedural nature marks tinkering as a continuous form of care: when something fails, new possibilities for action must be identified again and again. 


\section{FLOWERPOTS AND AFFORDANCES: ORDERING DEMENTIA}

Let me tell one last story. It starts with a member of the cleaning staff sweeping up the broken pieces of what once was a flowerpot. As I pass by, I peer up from the ground floor to the two upper floors, where the dementia wards are located. There, the remaining flowerpots are sitting in holders attached to the balustrades.

I step into the lift. The doors open onto the second floor's outer walking circuit. There I encounter Ms Velthof and Ms Smilde, sitting on their walkers next to the balustrade overlooking the ground floor. Ms Smilde, who I had come to know as a quiet and polite lady, seems to be worked up. She speaks as quietly as always but finishes fewer sentences than usual. Ms Velthof is also upset. She provides a lengthy explanation of the situation in perfectly articulated sentences: "We are both dumbfounded that we are here. They tell us all kinds of things, right? ... Short and well, put nicely: I'm totally disoriented, I do not understand how I got here; she also does not get it. We do know each other and neither of us know what all of this means, and they give us all kinds of sorry excuses. ... I was resting ... but the winds were so strong in my house! Well, this is not my house, but the noise was loud anyhow, so I got up and [pointing at Ms Smilde] ran into her. Therefore, disoriented as I am, I would like to know where I am."

I tell them that they are both suffering from memory loss, that they live here and that they receive care here. Ms Velthof gasps. "Care!?" She wants to know who brought her here and why she was not asked to sign for it. When I tell her that it was her partner, and that she did sign for it, I immediately realize that this was a stupid thing to say, because Ms Velthof begins to shout: "That's stupid! Not of me, but them! You surely can't drop a stupid woman who doesn't know anything somewhere with all kinds of shitty excuses? Excuse my language." Ms Velthof never forgets to politely apologize for her swearing. Calmer now, she tells me "Well, I 
threw that thing down with great joy!” I am surprised. I cannot help but ask, “You threw it?” I pause, and add, without thinking, "You could have hurt somebody!" Ms Velthof is not impressed with my reproach. "Of course I threw it! Because I am being hoodwinked (besodemieterd). Here, in this building. And I looked down first - nobody was walking below. I am not that crazy! ... What am I doing here? This is not my home.”

This situation lies at the heart of daily care for people with cognitive decline. It speaks to forgetfulness and disorientation, and the nursing home's attempts of remedying this by creating a sense of homeliness, such as attaching flowerpots to balustrades. The idea is that when residents feel more at home on the ward, they are less inclined to "want to go home" (cf. Reed-Danahay 2001; Buse and Twigg 2014). However, the decorative flowers failed to turn the ward into a homely space, and Ms Velthof threw the flowerpot over the balustrade to protest at her being locked-up in a strange place that she did not feel to be her home.

Practical and moral consequences to the subject positions exist, in which people move and are moved into, from where they are assumed to exert influence. Consider the responses to the flowerpot situation: I did not think that the flowerpot could have been thrown down, and responded too quickly with a concern for others' safety. When Janneke joins us at the balustrade, and asks what happened, Ms Velthof repeats that she has "thrown [down] those ugly dead, fake plants.” Being asked why, Ms Velthof, evidently still angry, declares loudly: "Because I am wrongly placed where I do not belong; because nobody can explain to me what I am doing here. ... Who has the right to lock me up here?"

Then care worker Eva approaches us. She explains to us that she received orders from the facility manager - somebody could get hurt should another pot "fall." She begins to remove the containers that are holding the remaining flowerpots. Then Ms Velthof tries to throw another flowerpot over the balustrade, but Eva stops her. An argument ensues and turns ugly, with reproaches flying back and forth. Eva turns to Janneke to say: "She really gets on my 
nerves. This really goes too far." Janneke agrees: "Yes, it really does. And she knows it." "She is ruining it for other people," comes Eva's final comment. They are joined by care worker Martina. Upon hearing what just happened, she looks around and her eyes linger on the halfdetached flowerpots. She says: "Well, I get it. I don't know why she cannot go downstairs like Mr Ritsma. She wants to go to the library. I have asked if they [the people responsible for the books corner] can send up some books."

The following week, the team invited the in-house psychologist for an Omgangsoverleg, a meeting to discuss how to better care for one particular resident. The team recounts their versions of what happened: Ms Velthof "went too far" in throwing a flowerpot; she "knew what she was doing," she was "ruining it for other people." They describe Ms Velthof as becoming more difficult to handle. The psychologist listens, asks questions, and finally sums up his advice: Ms Velthof is highly educated among women of her time [born late 1920s]. She was a university professor, used to being treated with recognition given her professional status. Finding none of this in the nursing home (Ms Velthof often complained to me about being spoken to in the same way people sometimes speak down to children), and lacking an understanding of how she got here, she must be frustrated. He reminds them that this is "the disease progressing." He instructs the team to acknowledge Ms Velthof's social position, and that this could alleviate her "behavior."

Now recall Martina's response. In her suggestion to bring up books to counter her throwing more flowerpots, the building is understood not merely as a background to care, but as actively affording particular actions, while prohibiting others. As long as it is not acknowledged that architectural elements afford specific actions, it seems as if Ms Velthof is the single author of that action. Without the balustrade overviewing the lower floors, Ms Velthof could not have thrown the flowerpot. The balustrade, with its designers' ideals of spaciousness and openness built in, affords - but does not determine - specific activities. 
Attesting to other affordances, physiotherapist Thomas tells me that residents of the upper floors often wave to him on the ground floor.

Whether the throwing of the flowerpot is a sign of advancing dementia or not, matters for what positions are enacted for Ms Velthof, and what interventions are chosen. When Ms Velthof "knows what she is doing" she is enacted as mean and difficult, and thus in need of reprimanding. By stating that her dementia "is progressing," the psychotherapist enacts Ms Velthof as a person with a pathology that excuses her throwing flowerpots. In this ordering, reprimanding her will not do much. In the suggestion to bring her books, Ms Velthof is enacted as a person in need of something to read, blurring the binary of innocence or responsibility. When Martina, rather than accepting that "this is what the building does," attributes the throwing of the flowerpot to the absence of books, she explores her own possibilities to act. Doing so requires a certain sociomaterial awareness, which, I suggest is crucial to improving dementia care, as it opens up possibilities to enact better ways of living on the ward. The care workers' tinkering may result in Ms Velthof feeling less frustrated, less restricted, and throwing fewer flowerpots.

\section{CONCLUDING REMARKS: ENACTING BETTER WAYS OF LIVING}

My analysis above interferes with the practices of critique that seek to improve care practice from the outside or "top down." Previous research on built environments rarely accounts for the interaction between the built environment and its users, other than in relation to design and construction. In telling stories of the situated practices that assembled relations differently, to enact different ways of living with dementia on the ward, I have extended this work by coining the term "sociomaterial awareness." I have used the term to refer to a (collective) situational sensitivity to the ways in which the built environment invites its users (professionals, but also people with dementia themselves) to act in specific ways. It brings into view possibilities of 
adjusting elements of built environments, as part of everyday care practices to enact different ways of living on the ward.

With this analysis, I hope to have opened up a space for sociomaterial awareness to become appreciated and shared. I have pointed to ways in which dementia care practice can be improved, while the specificity of situations is kept in full view. Sociomaterial awareness does not guarantee complete or even durable solutions: the key that care workers gave Ms Maren for instance, did not have the desired effect, although it did at least allow other people, like visiting family members and me, to let her into her room. Tinkering will sometimes fail to produce improvements, and may provoke more questions, pointing to the on-going nature of care. If doors are unlocked, and there are no lockers (yet), can we expect family members to put up with a second denture disappearing within only a few months? How to deal with a broken hip that resulted from a fight between a resident who got into the wrong bed, and the resident whose bed it was?

What is important is not to count these failures, but value the ongoing attempts to create an openness in which experimenting to improve lives on the ward becomes possible (D'Hoop 2018:148), in which activity is meaningful, incontinence can be staved off as long as possible, and life is lived, even if at times unsafely. Tinkering can help restore and support everyday lives that are valuable for individual residents.

In addition, what dementia is in those practices changes altogether. Rather than enacting what residents do as problematic, or as sign of their progressing dementia, I have demonstrated how building-user interactions are co-constitutive of that which is often read as "a symptom": toilet doors, keys, and those who hold and use them to lock doors play a role in the production of incontinence. "Lazy chairs" coproduce inactivity. Closed doors and balustrades conjure up frustrations and aggression. As a result, the stories told interfere with the enactment of dementia as a condition with a predictable course of decline. Sociomaterial awareness opens up 
possibilities to order dementia differently, to enable other interactions, other care, other lives. Because of this, I suggest that there is still much to be learned from care practices as generative of better lives for people with dementia.

My analysis also offers lessons for ethnographers: contemplating sociomateriality in our analytics goes beyond describing built environments and their design as "context" - it requires signalling buildings as actors. Donna Haraway's reiteration of Marilyn Strathern voices the argument and appeal that making relations in specific ways makes worlds: "It matters what matters we use to think other matters with; it matters what stories we tell to tell other stories with; it matters what knots knot knots, what thoughts think thoughts, what ties tie ties. It matters what stories make worlds, what worlds make stories" (Haraway 2016:12). Hence, whether and how buildings and building-user interactions feature in our writing is important. We must attend to which entities make what kinds of difference. To do so we may learn from those who work and live in that environment by paying close attention to practices, in all their diversity (cf. d'Hoop 2018).

In the interplay between the building and its users, the social life of the ward unfolds. Ms Velthof may live feeling locked up and frustrated, live with the label of being "mean," only to be reprimanded for ruining everything for others; she may be drugged, living in a haze; or she may live with access to books. With these analyses, while constantly keeping the specificities of residents and settings in mind, it becomes possible to compare them. We may ask whether physical safety should be valued over residents' freedom of movement, or vice versa, and accept the accompanying risks (cf. Bland 1999; Driessen, Van der Klift, and Krause 2017; Jennings 2001). Do we value the time saved when lifts are stored in bathrooms that are closed to those who need them? Or, is it more important to allow those few who can independently find and use the bathroom to do so? Do we wish to keep residents with dementia under supervision, and tolerate that they spend time waiting in front of their doors, or do we 
open doors to allow them to stop waiting? In asking what kind of life is lived here and now, and by contrasting different lives, the ways in which people are enacted and enacting themselves, which underpin different ways of living, can be weighed against one another. Doing so allows us to begin to answer the important question posed by Moser $(2008,2006)$ : Which realities do we want to live with? 


\section{ACKNOWLEDGEMENTS}

The research was preapproved by the Ethical Committee of the Amsterdam Institute of Social Science Research at the University of Amsterdam, the Netherlands. I would like to thank in particular the residents and care professionals with whom I worked over the years, for sharing their time with me, and for teaching me so much. I am grateful to Ariane d'Hoop, Annekatrin Skeide, Rebecca Lynch and two anonymous reviewers for their feedback on earlier versions of this article. I want to thank Jeannette Pols and Kristine Krause whose inspiration and support were crucial for my research and the writing of this article.

\section{FUNDING}

This research project was funded by the Gieskes Strijbis Fonds. 


\section{REFERENCES}

Barnes, $S$.

2006. Space, choice and control, and quality of life in care settings for older people.

Environment and Behavior 38(5): 589-604.

Berg, M., and A. Mol.

1998. Differences in Medicine: Unraveling Practices, Techniques, and Bodies. Durham, NC: Duke University Press.

Bland, R.

1999. Independence, privacy and risk: Two contrasting approaches to residential care for older people. Ageing and Society 5:539-60.

Brand, S.

1995. How Buildings Learn: What Happens After They're Built. New York: Penguin Books.

Buse, C., S. Nettleton, D. Martin, and J. Twigg.

2016. Imagined bodies: Architects and their constructions of later life. Ageing and Society 1-23.

Buse, C. and J. Twigg.

2014. Women with dementia and their handbags: Negotiating identity, privacy and 'home' through material culture. Journal of Aging Studies 30:14-22.

D’Hoop, A.

2018. Modest Attachments. An Inquiry into the Potentialities of Material Spaces in a Psychiatric Day Care Centre. PhD dissertation, Department of Anthropology, University 
of Amsterdam, the Netherlands, and Department of Architecture, Université Libre de Bruxelles, Belgium.

Devlin, A. S. and A. B. Arneill.

2003. Health care environments and patient outcomes: A review of the literature.

Environment and Behavior 35(5): 665-94.

Dewing, J.

2007. Participatory research: A method for process consent with persons who have dementia. Dementia 6(1): 11-25

Driessen, A., I. van der Klift, and K. Krause,

2017. Freedom in dementia care? On becoming better bound to the nursing home.

Etnofoor 29(1): 29-41.

Gieryn, T. F.

2002. What buildings do. Theory and Society $31: 35-74$.

Goffman, E.

1961. Asylums. Essays on the Social Situation of Mental Patients and Other Inmates.

Harmondsworth, UK: Penguin.

Haraway, D. J.

1988. Situated knowledges: The science question in feminism and the privilege of partial perspective. Feminist Studies 14(3): 575-99.

. 2016. Playing string figures with companion species. In Staying with the Trouble:

Making Kin in the Cthulucene, pp. 9-29. Durham, NC: Duke University Press. 
Hughes, J. C., S. J. Louw, and S. R. Sabat, eds.

2005. Dementia: Mind, Meaning, and the Person. Oxford, UK: Oxford University Press.

Jennings, B.

2001. Freedom fading: On dementia, best interests, and public safety. Georgia Law Review 35(2): 593-619.

Kitwood, T.

1997. Dementia Reconsidered: The Person Comes First. Maidenhead, UK: Open University Press.

Kontos, P. C.

2004. Ethnographic reflections on selfhood, embodiment and Alzheimer's Disease. Ageing and Society 24(6): 829-849.

Koolhaas, R., AMO and Harvard Graduate School of Design.

2014. Elements. J.Wescott, ed. Venice, Italy: Marsilio.

Latour, B.

1988. Mixing humans and nonhumans together: The sociology of a door-closer. Social Problems 35 (3): 298-310.

Law, J.

1992. Notes on the theory of the actor-network: Ordering, strategy, and heterogeneity. Systems Practice 5(4): 379-393.

1994. Organizing Modernity. Oxford, UK: Blackwell.

2009. Actor Network Theory and material semiotics. In The Blackwell Companion 
to Social Theory. B.S. Turner, ed. Pp. 141-158. Oxford, UK: Wiley-Blackwell.

Law, J. and A. Mol.

2008. The actor-enacted: Cumbrian sheep in 2001. In Material Agency: Towards a NonAnthropocentric Approach, C. Knappett and L. Malafouris, ed. Pp. 57-77. New York: Springer.

Martin, D., S. Nettleton, S. Buse, L. Prior, and J. Twigg. 2015. Architecture and health care: A place for sociology. Sociology of Health \& Illness 37(7): 1007-1022.

McColgan, G.

2005. A place to sit: Resistance strategies used to create privacy and home by people with Dementia. Journal of Contemporary Ethnography 34(4): 410-433.

Mol, A.

2002. The Body Multiple: Ontology in Medical Practice. Durham, NC and London: Duke University Press.

— 2008. The Logic of Care: Health and the Problem of Patient Choice. London: Routledge.

2010. Actor-Network Theory: Sensitive terms and enduring tensions. Kölner Zeitschrift Für Soziologie Und Sozialpsychologie 50(1): 253-269.

Mol, A., I. Moser, and J. Pols, eds.

2010. Care in Practice: On Tinkering in Clinics, Homes and Farms. Bielefeld, Germany: Transcript. 


\section{Moser, I.}

2005. On becoming disabled and articulating alternatives. The multiple modes of ordering disability and their interferences. Cultural Studies 19(6): 667-700.

. 2006. Sociotechnical practices and difference: On the interferences between disability, gender, and class. Science, Technology, \& Human Values 31(5): 537-564.

_. 2008. Making Alzheimer's Disease matter. Enacting, interfering and doing politics of nature. Geoforum 39:98-110.

- 2011. Dementia and the limits to life: Anthropological sensibilities, STS interferences, and possibilities for action in care. Science, Technology, \& Human Values 36(5): 704-722.

Moser, I. and J. Law.

1999. Good passages, bad passages. The Sociological Review 47 (S1): 196-219.

Nord, C.

2011a. Architectural space as a moulding factor of care practices and resident privacy in assisted living. Ageing and Society 31: 934-952.

. 2011b. Individual care and personal space in assisted living in Sweden. Health \& Place 17(1): 50-56.

Van Oorschot, W.

2006. The Dutch welfare state: Recent trends and challenges in historical perspective. European Journal of Social Security 8(1): 57-76.

Pols, J. 
2011. Breathtaking practicalities: A politics of embodied patient positions. Scandinavian Journal of Disability Research 13(3): 189-206.

Reed-Danahay, D.

2001. 'This is your home now!': Conceptualizing location and dislocation in a dementia unit. Qualitative Research 1(1): 47-63.

Targhi Bakkali, H.

2016. Verlangen we straks terug naar de verzorgingshuizen van nu? De Correspondent. https://decorrespondent.nl/4701/Verlangen-we-straks-terug-naar-de-verzorgingshuizenvan-nu-/617216859501-837b4453.

Taylor, J. S.

2014. The demise of the bumbler and the crock: From experience to accountability in medical education and ethnography. American Anthropologist 116 (3): 1-12.

Twigg, J.

2000. Bathing - The Body and Community Care. London: Routledge.

Verbraeck, B. and A. van der Plaats.

2016. De Wondere Wereld van Dementie: Vanuit Nieuwe Inzichten Omgevingszorg Bieden Aan Dementerenden. Third ed. Houten, the Netherlands: Bohn Stafleu van Loghum Springer Media BV.

Vogel, E.

2014. Clinical specificities in obesity care: The transformations and dissolution of 'will' and 'dives.' Health Care Analysis 24 (4): 321-37.

2016. Subjects of Care: Living with Overweight in the Netherlands. University of 
Amsterdam, the Netherlands.

https://dare.uva.nl/search?field1=keyword;value1=vogel;docsPerPage=1;startDoc=1.

2017. Hungers that need feeding: On the normativity of mindful nourishment. Anthropology \& Medicine 24(2): 159-173.

Vos, F. de

2013. 8 Belangrijke Omgevingsfactoren Voor Mensen Met Dementie. ZorgInstellingen http://www.studiodvo.com/wp-content/uploads/2011/08/2013-09-artikel-FionaZorginstellingen-sept.pdf.

Wigg, J. M.

2010. Liberating the wanderers: Using technology to unlock doors for those living with dementia. Sociology of Health \& Illness 32(2): 288-303.

Yaneva, A.

2009. Making the social hold: Towards an Actor-Network theory of design. Design and Culture 1(3): 273-288.

Zuiderent-Jerak, T.

2010. Embodied Interventions - Interventions on bodies: Experiments in practices of Science and Technology Studies and hemophilia care. Science, Technology, \& Human Values 35(5): 677-710. 


\section{Notes}

1 "Problem behavior" is now more commonly called "poorly understood behavior." This change in terminology is an important move towards acknowledging that actions, although perceived as problematic, are likely to have a reason thus far not been recognized. This generates possibilities to pay attention and be curious. Here, I choose to avoid the word "behavior" altogether, as it still seems to pinpoint normatively the individual as the center of socially unacceptable conduct. In an attempt to describe what people do in a more neutral way, I use "activities" instead.

${ }^{2}$ At night, most residents wore incontinence pads.

${ }^{3}$ This should not be held in opposition to a biomedical approach to dementia. I build on work that argues against delineating biomedicine as the domain with the exclusive right to speak about bodies and diseases (cf. Mol 2002:11-22), or approaching it as one coherent body of knowledge (Berg and Mol 1998; Moser 2011). This work urges scholars to study biomedicine as only one site in which categories and realities are made in their many versions.

${ }^{4}$ The Architectural Elements series by Rem Koolhaas in collaboration with the Harvard Graduate School of Design (2014), consists of 14 books, each dedicated to one architectural element which together make up the fundamentals of buildings: floors, walls, ceilings, roofs, doors, windows, facades, balconies, corridors, fireplaces, toilets, stairs, escalators, elevators and ramps. I thank Ariane d'Hoop for bringing this series to my attention.

${ }^{5}$ In the material semiotic tradition, agency analytically does not require intentionality. Drawing on Latour's “actors as entities" (1988) and Haraway's "making a difference” (1988), Mol and Law state it as follows: "An entity counts if it makes a perceptible difference" (2008:58). Agency, then, is distributed between humans and non-humans, with 
each shaping, impinging on and mediating the capacity of other agents to act. A building here is not so much a conscious actor, but an actor nonetheless.

${ }^{6}$ Nursing homes and participants were ascribed pseudonyms to ensure anonymity. I use first or last names according to how people were addressed in the situations described.

${ }^{7}$ For a defense of the anthropological practice of letting oneself be surprised by one's field, see Taylor 2014.

${ }^{8}$ For budgetary reasons, care workers had arranged for second hand furniture to be available Some of the couches were easy to get into, but hard to get up from. Residents had to be helped back up to be able to move back to the dining table. The example, even if it did not quite work out as planned in the beginning, highlights how care workers tinkered, as well as how even small details matter: even the kind of furniture matters for which kinds of activities are enabled and encouraged.

${ }^{9}$ The importance of privacy has been frequently emphasized, and its lack in nursing homes has often been subject to critique (e.g. Bland 1999; Nord 2011a; Twigg 2000). A critique of locked doors of resident rooms, but also the closed-door policy pertaining to the ward exit and main entrance (see for instance Jennings 2001), was also voiced within De Parkhoeve. However, organizational change takes time; meanwhile residents could not access their rooms.

${ }^{10}$ The reference is to Latour, who writes about hotel managers who attach a weight to keys so as to delegate to the object the task of reminding their guests to return them to the front desk (1988).

${ }^{11}$ There is much to be gained here when cognition is acknowledged to be only one of the many capacities that allow us to recognize something. Inspiring examples explore tactility and muscle memory in relation to elements of the built environment. In her project "Keep on dwelling after all" (https://www.keepondwelling.com/), for example, Masha Soetekouw works with people with dementia who live in residential dementia care to create their own 
hand-made door handles. First using clay to find the right shape, then making a mold with silicone, Masha and each resident produce a plastic handle in colours of the resident's choosing. The handle facilitates orientation on the ward through its appeal to tactile memories and the changed relationship that residents have with "their" door knob.

${ }^{12}$ Following Zuiderent-Jerak I prefer to speak of "alterations" rather than solutions. The term alterations, he suggests, creates a sensitivity for new issues that arise in the wake of the intervention (2010:678-79). 